\title{
Jatkuvasatoisilla lajikkeilla mansikkaa kesästä syksyyn
}

Tarja Hietaranta ja Saila Karhu

MTT Kasvintuotannon tutkimus, Puutarhatuotanto, Toivonlinnantie 518, 21500 Piikkiö etunimi.sukunimi@mtt.fi

\section{Tiivistelmä}

Jatkuvasatoiset mansikat muodostavat kukka-aikeita joko pitkänpäivän olosuhteissa tai päivänpituudesta riippumatta, ja molemmat kukintatyypit soveltuvat mansikansatokauden pidentämiseen Suomen olosuhteissa. MTT puutarhatuotannossa Piikkiössä on vuosina 2008-2009 testattu ulkomaisia jatkuvasatoisia mansikkalajikkeita osana tutkimushanketta MANSIKKAREMONTTI - Mansikantuotannon kannattavuuden lisääminen jatkuvasatoisten lajikkeiden avulla.

Kokeet perustettiin muovikatteiseen kausihuoneeseen, jonne koekasvit istutettiin tippukastelulaittein varustettuihin viljelysäkkeihin toukokuun lopulla. Vuonna 2008 testattiin 13 lajiketta: hollantilaiset siemenlisättävät 'Durban', 'Elan' ja 'Milan', ruotsalainen 'Elin', englantilaiset 'Flamenco', 'Malling Opal', 'Malling Pearl' ja 'Tango', australialaiset 'Kalinda' ja 'Lowanna', norjalaiset 'Rita' ja 'Rondo' sekä kalifornialainen 'Selva'. Lisäksi testattiin neljä nimeämätöntä jalostetta: englantilainen 354/G1, sekä kanadalaiset FIN0016-115, FIN008-124 ja FIN132-11. Satokausi alkoi kokeessa heinäkuun alussa, mutta sadon kertyi kunnolla vasta elokuun puolivälistä alkaen. Marjaa tuottaneiden koelajikkeiden kokonaissadot vaihtelivat 150 grammasta lähes 1000 grammaan kasvia kohden. Satoisimmat lajikkeet olivat 'Durban', 'Elan', 'Rondo', 'Flamenco' ja 'Malling Opal'. 'Selva' ja' Tango' eivät kukkineet kokeen aikana. Härmää esiintyi tunneliviljelyssä paljon, eikä yksikään lajikkeista ollut täysin härmänkestävä. Vähiten härmäisiä marjoja esiintyi Flamenco-lajikkeessa. Eri lajikkeiden härmänkestävyyserot olivat suuret.

Lajikekoe jatkui vuonna 2009 yhdeksällä edellisvuoden kokeesta valitulla koejäsenellä: 'Durban', 'Elan', FIN132-11, 'Flamenco', 'Lowanna', 'Malling Opal', 'Malling Pearl', 'Rondo' ja 'Selva'. Uusina koejäseninä lajikevertailuun liitettiin 'Tribute', 'Premier', 'Promise' ja 'Valor'. Lannoitustaso oli edellistä vuotta alhaisempi ja sadot kasvia kohden vaihtelivat alle 400 grammasta lähes 850 grammaan. Parhaiten satoa tuottivat 'Durban', 'Malling Opal', 'Malling Pearl', 'Tribute', 'Lowanna', 'Elan' ja 'Promise'. 'Selva' ei kukkinut eikä tuottanut satoa. Härmäisten marjojen osuus oli pienin Malling Opal - ja Malling Pearl -lajikkeiden sadoissa.

Lajikkeiden välillä oli suuria eroja marjan laadun, esimerkiksi kiinteyden ja maun suhteen. Penetrometrillä mitattuna kiinteimpiä koejäseniä olivat 'Flamenco' ja FIN132-11. Makuarviot vaihtelivat, mutta miellyttävän makuisiksi arvosteltiin 'Elan', 'Malling Opal', 'Malling Pearl', 'Rita' ja 'Rondo'.

Ensimmäisen lajikekokeen yhteydessä toteutettiin taimikoe, jossa verrattiin siemenestä lisättyjen lajikkeiden eripituisten taimikasvatusaikojen vaikutusta sadontuottokykyyn. Kahden taimierän kylvöt tehtiin istutusta edeltävän vuoden touko- ja heinäkuussa ja esikasvatetut taimet frigovarastoitiin talven yli. Esikasvatettuja taimia verrattiin taimiin, jotka oli kylvetty istutusvuoden helmikuussa. Pitkä taimikasvatus aikaistutti sadon alkamista ja lisäsi kokonaissatoa Durban- ja Milan-lajikkeilla.

Vuonna 2009 tehtiin myös taimikoe, jossa keväällä taimikasvatettujen kasvien sadontuottopotentiaalia verrattiin vuotta vanhempien kasvien sadontuottoon. Vertailu osoitti, että vuoden vanhat kasvit tuottivat aikaisemman ja joillakin lajikkeilla jopa kaksi kertaa suuremman kokonaissadon kuin keväällä kasvatetut taimet.

\section{Asiasanat}

lajikkeet, mansikat, taimikasvatus 


\section{Johdanto}

Tavalliset sesonkisatoiset puutarhamansikat muodostavat kukka-aiheensa lyhyenpäivän olosuhteissa syksyllä. Kukka-aiheet talvehtivat kasvien juurakoissa ja jatkavat kehitystään keväällä. Lyhyenpäivän mansikat tuottavat kesässä yhden sadon. Jatkuvasatoiset kykenevät tuottamaan satoa useammassa jaksossa kasvukauden aikana. Ne muodostavat kukka-aiheita joko pitkänpäivän olosuhteissa tai päivänpituudesta riippumatta. Molemmat jatkuvasatoiset kukintatyypit soveltuvat mansikansatokauden pidentämiseen Suomen olosuhteissa. MTT puutarhatuotannossa Piikkiössä on vuosina 2008-2009 testattu ulkomaisia jatkuvasatoisia mansikkalajikkeita osana tutkimushanketta MANSIKKAREMONTTI Mansikantuotannon kannattavuuden lisääminen jatkuvasatoisten lajikkeiden avulla (Hietaranta \& Karhu, 2008).

\section{Aineisto ja menetelmät}

Kokeet perustettiin muovikatteiseen lämmittämättömään kausihuoneeseen, joka rakennettiin ilmanvaihdon edistämiseksi vallitsevien tuulten suuntaisesti. Huoneen päädyt poistettiin kesäkaudeksi kokonaan. Koekasvit istutettiin tippukastelulaittein varustettuihin viljelysäkkeihin toukokuun lopulla. Kasvullisesti lisättävien lajikkeiden taimet kasvatettiin mikrolisätyistä emokasveista otetuista rönsytaimista keväällä. Kolme lajikkeista lisättiin siemenkylvöillä. Kaikista koejäsenistä istutettiin neljä kuuden kasvin kerrannetta. Automaattinen kastelujärjestelmä oli säädetty ottamaan huomioon kertyvä auringon säteilymäärä ja kasteluveden johtoluvuksi säädettiin vuonna 2008 1,5 mS/cm:iin. Kasveja lannoitettiin pääsääntöisesti joka kastelukerralla. Vuonna 2008 testattiin 13 lajiketta: hollantilaiset siemenlisättävät 'Durban', 'Elan' ja 'Milan', ruotsalainen 'Elin', englantilaiset 'Flamenco', 'Malling Opal', 'Malling Pearl' ja 'Tango', australialaiset 'Kalinda' ja 'Lowanna', norjalaiset 'Rita' ja 'Rondo' sekä kalifornialainen 'Selva'. Lisäksi testattiin neljä nimeämätöntä jalostetta: englantilainen 354/G1, sekä kanadalaiset FIN0016-115, FIN008-124 ja FIN132-11. Koekasvustoista torjuttiin härmää tarpeen mukaan kemiallisilla torjunta-aineilla. Lisäksi härmäntorjuntaan käytettiin rikittimiä. Lajikkeista kerättiin satoa lokakuulle sekä havainnointiin ja mitattiin kasvusto- ja marjaominaisuudet.

Lajikekoe jatkui vuonna 2009 yhdeksällä edellisvuoden kokeesta valitulla koejäsenellä: 'Durban', 'Elan', FIN132-11, 'Flamenco', 'Lowanna', 'Malling Opal', 'Malling Pearl', 'Rondo' ja 'Selva'. Edellisvuoden kokemusten perusteella kasteluveden johtoluku säädettiin alhaisemmaksi 0,7 mS/cm:iin. Uusina koejäseninä lajikevertailuun liitettiin USA:n Marylandissa jalostettu 'Tribute' sekä kalifornialaiset lajikkeet 'Premier', 'Promise' ja 'Valor'. Kalifornialaiset lajikkeet hankittiin frigotaimina jotka istutettiin viljelysäkkeihin toukokuun alussa. Taimia pidettiin karanteenissa eristetyssä kasvihuoneessa, kunnes niiden puhtaus kasvintuhoojista oli varmistettu. Kausihuoneen lajikekokeeseen 'Premier', 'Promise' ja 'Valor' siirrettiin 22.6. Lajikevertailun lisäksi kokeeseen sisällytettiin myös kahdeksalla lajikkeella taimikoe, jossa keväällä taimikasvatettujen kasvien sadontuottopotentiaalia verrattiin vuotta vanhempien, frigovarastoitujen, kasvien sadontuottoon.

Vuoden 2008 lajikekokeen yhteydessä toteutettiin myös taimikoe, jossa verrattiin siemenestä lisättyjen lajikkeiden - 'Durban', 'Elan' ja 'Milan' - eripituisten taimikasvatusaikojen vaikutusta sadontuottokykyyn. Kahden taimierän kylvöt tehtiin istutusta edeltävän vuoden touko- ja heinäkuussa ja esikasvatetut taimet frigovarastoitiin talven yli. Esikasvatettuja taimia verrattiin taimiin, jotka oli kylvetty istutusvuoden helmikuussa.

\section{Tulokset ja tulosten tarkastelu}

\section{Lajikekokeet}

Vuonna 2008 satokausi käynnistyi kokeessa heinäkuun alussa, mutta sadon kertyminen alkoi kunnolla vasta elokuun puolivälin jälkeen. Marjaa tuottaneiden koelajikkeiden kokonaissadot vaihtelivat 150 grammasta lähes 1000 grammaan kasvia kohden (Kuva 1). Satoisimmat lajikkeet olivat 'Durban', 'Elan', 'Rondo', 'Flamenco' ja 'Malling Opal'. 'Selva' ja' Tango' eivät kukkineet ja tuottaneet satoa kokeen aikana. Härmää esiintyi tunneliviljelyssä paljon, eikä yksikään lajikkeista ollut täysin härmänkestävä. Vähiten härmäisiä marjoja esiintyi Flamenco-lajikkeessa ja jalosteessa FIN0016-115, joka tuotti vain vähän satoa. Eri lajikkeiden härmänkestävyyserot olivat suuret ja jaloste 354/G1 poistettiin kokeesta alkuvaiheessa härmänalttiuden vuoksi. Lajikkeiden välillä oli suuria eroja marjan laadun, 
esimerkiksi kiinteyden ja maun suhteen. Penetrometrillä mitattuna kiinteimpiä koejäseniä olivat 'Flamenco', FIN0016-115 ja FIN132-11. Sormin hieroen kestäväpintaisimpia lajikkeita olivat 'Kalinda' ja 'Malling Opal'. Parhaimman makuisiksi arvosteltiin 'Rondo', 'Malling Opal' ja 'Rita'.

Vuoden 2009 satokausi alkoi heinäkuun alkupuoliskolla ja eri lajikkeiden kokonaissadot kasvia kohden vaihtelivat alle 400 grammasta lähes 850 grammaan (Kuva 2). Lannoitustaso oli edellistä vuotta alhaisempi ja parhaiten satoa tuottivat 'Durban', 'Malling Opal', 'Malling Pearl', 'Tribute', 'Lowanna', 'Elan' ja 'Promise'. 'Selva' käyttäytyi samalla tavoin kuin edellisenä vuonna, eivätkä keväällä rönsytaimista lisätyt kasvit kukkineet. Kalifornialaisten lajikkeiden - 'Premier', 'Promise' ja 'Valor' - taimet olivat eri alkuperää kuin muiden koejäsenten taimet, eivätkä satotulokset ole täysin vertailukelpoisia muiden kanssa. Mansikkahärmää esiintyi kaikissa lajikkeissa. Parhaiten härmää kestivät 'Malling Opal' ja 'Malling Pearl'. Miellyttävimmän makuisiksi arvioitiin 'Elan', 'Malling Pearl' ja 'Rondo'. Durban-lajikkeen mausta ei pidetty. 'Flamenco' ja FIN132-11 olivat penetrometrilla mitattuna kiinteimpien lajikkeiden joukossa myös toisena koevuonna. Niiden pinta arvosteltiin myös kestävimmäksi.

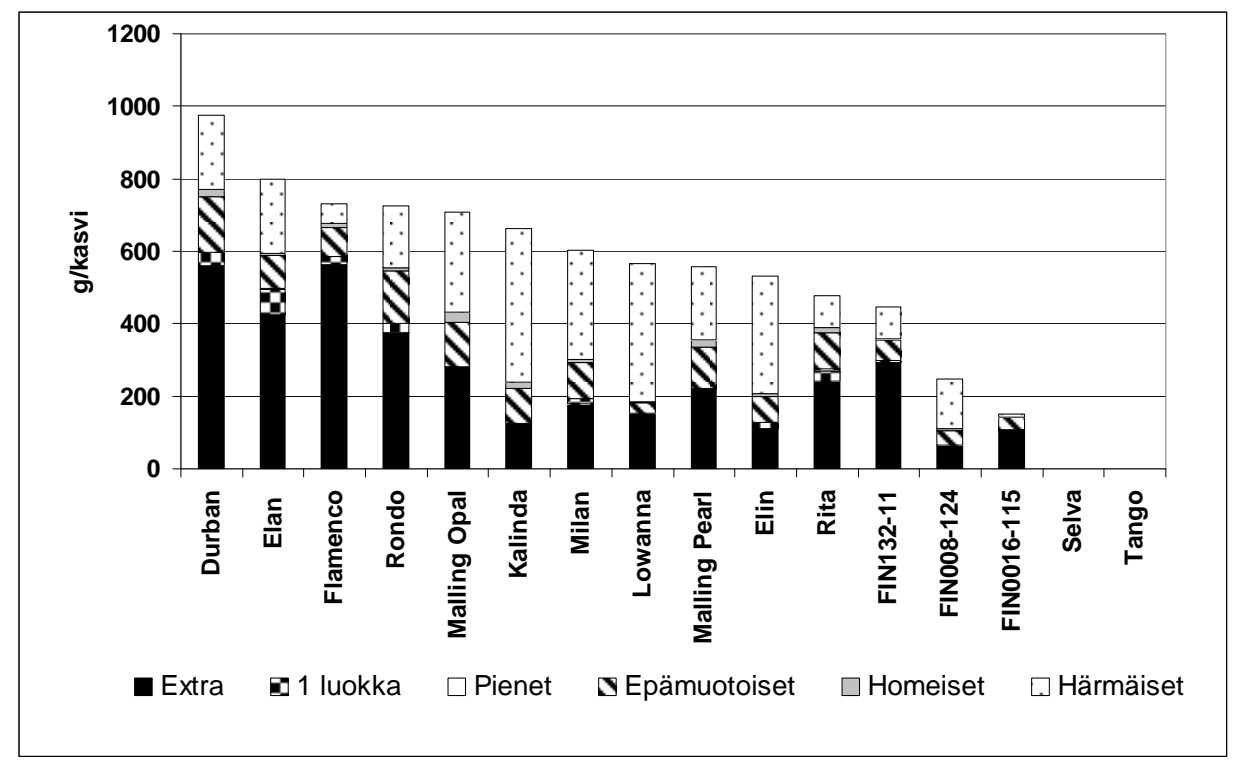

Kuva 1. Vuoden 2008 lajikekokeen kasvikohtaiset kokonaissadot sadonkorjuuluokittain.

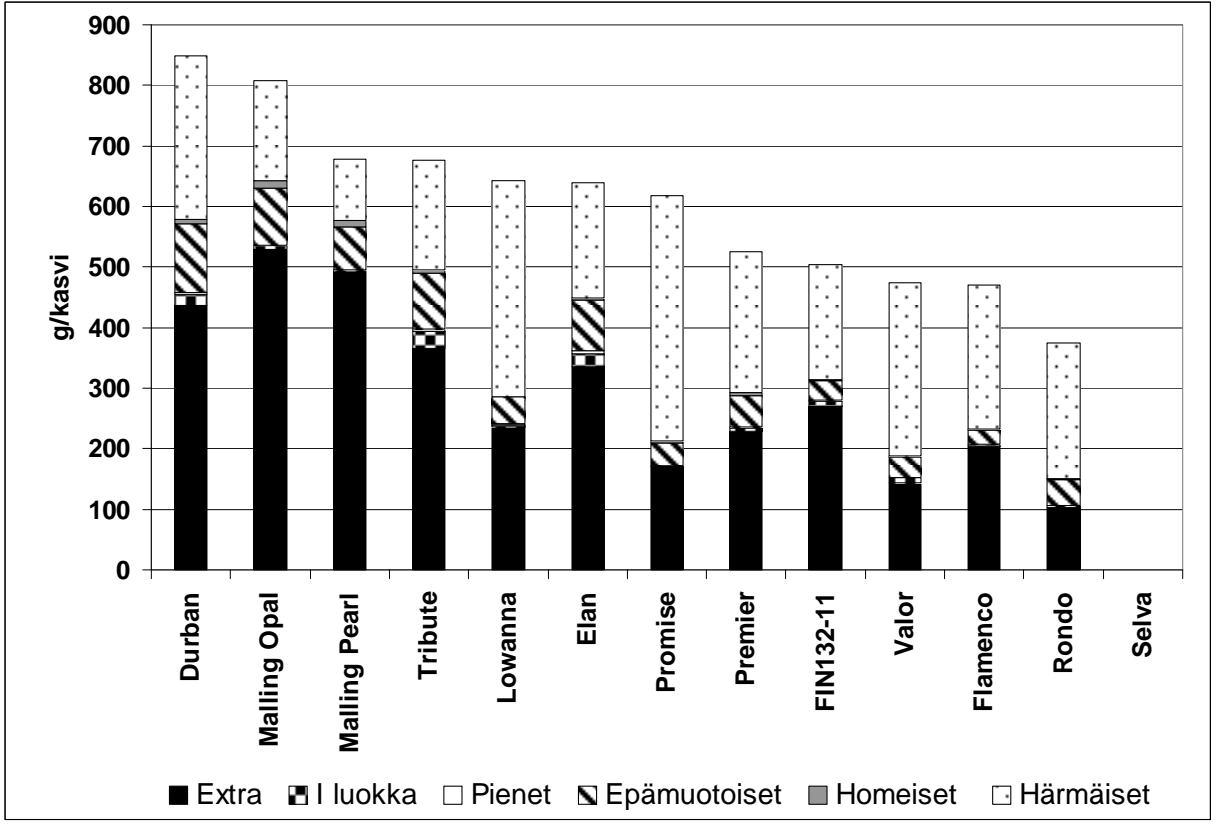

Kuva 2. Vuoden 2009 lajikekokeen kasvikohtaiset kokonaissadot sadonkorjuuluokittain. 


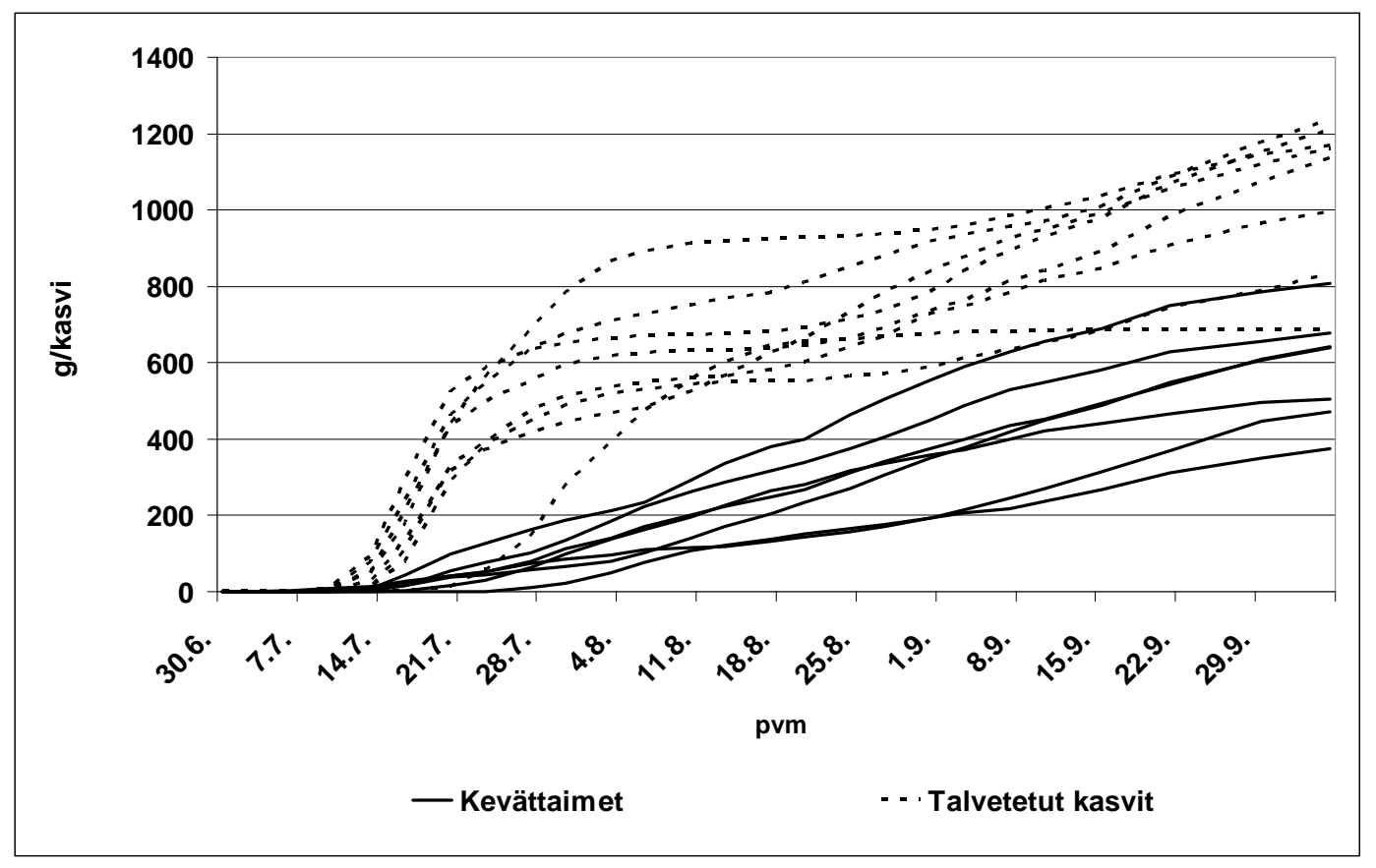

Kuva 3. Keväällä taimikasvatettujen (Kevättaimet) ja vuotta vanhempien, frigovarastossa talvetettujen kasvien (Talvetetut kasvit) kumulatiivinen sato vuonna 2009.

\section{Taimikokeet}

Keväällä taimikasvatettujen ja vuotta vanhempien, frigovarastossa talvetettujen taimien vertailu osoitti, että vuoden vanhat, jo yhden sadon antaneet kasvit tuottivat aikaisemman ja suuremman, joillakin lajikkeilla jopa kaksi kertaa suuremman kokonaissadon kuin keväällä kasvatetut taimet (Kuva 3). Toisaalta useimmilla lajikkeilla talvetettujen kasvien marjat olivat hieman pienempiä kuin keväällä kasvatettujen taimien marjat. Siemenlisättävien lajikkeiden pitkä taimikasvatus aikaistutti sadon alkamista ja lisäsi kokonaissatoa Durban- ja Milan-lajikkeilla mutta ei Elan-lajikkeella.

\section{Johtopäätökset}

Lajikekokeen perusteella ei voida yksiselitteisesti suosittaa lajikkeita jatkuvasatoisten mansikoiden kausihuoneviljelyyn. Osalla lajikkeista on hyviä sadontuotto- ja laatuominaisuuksia mutta myös rajoittavia tekijöitä. Mansikkahärmä on yksi kausihuoneissa toteutettavan mansikanviljelyn keskeisimmistä ongelmista. Viljeltävän lajikkeen hyvä härmänkestävyys on kannattavan tuotannon kannalta merkittävä ominaisuus. Koeolosuhteissa, joissa taimimateriaali oli puhdasta eikä maalevintäisten sienitautien leviämismahdollisuutta ollut, vaikuttavat 'Malling Opal' ja 'Malling 'Pearl' härmänkestävyyden, sadontuottokyvyn ja marjaominaisuuksien suhteen kiinnostavilta lajikkeita. Viljelykelpoisuuden arvioinnissa tulee kuitenkin vielä ottaa huomioon muun muassa tyvimädänkestävyys, mikä ei lajikekokeen järjestelyissä tullut esille. Satoisan Durban-lajikkeen heikoin ominaisuus on maku. Hyvänmakuinen Rondo-lajike oli toisen vuoden kokeessa heikkosatoisin, ja viljelyyn valittavalle lajikkeelle tulisikin määrittää optimaalinen lannoitustaso. Rondo-lajikkeen puutteita ovat pehmeät marjat ja hyvin tumma väri.

Jos viljelmällä on mahdollisuudet kokeessamme käytettyyn viljelymenetelmään ja kylmävarastointiin, kannattaa kasvit hyödyntää ainakin kaksivuotisesti sadontuottoon: Jo yhden sadon tuottaneiden, frigovarastossa kasvatussäkeissä talvetettujen kasvien käytöllä on lajikkeesta riippuen mahdollista aikaistaa ja lisätä kokonaissatoa. Myös aikaistetulla taimikasvatuksella pystyttiin jonkin verran lisäämään ja aikaistamaan siemenlisättyjen lajikkeiden satoa mutta vain kahdella kolmesta lajikkeesta.

\section{Kirjallisuus}

Hietaranta, T., Karhu, S. 2008. Jatkuvasatoista mansikkaa pitkälle syksyyn. Puutarha\& kauppa 12, 25-26: 14-15. 